\title{
Genes asociados al proceso carioso
}

\author{
Genes associated with the carious process \\ Karen Fernanda Orozco Mateo, ${ }^{\star}$ Martha Graciela Fuentes Lerma, ${ }^{\ddagger}$, \\ Melva Gutiérrez Angulo, $\S$ Rocío Patricia Mariaud Schmidt ${ }^{\ddagger}$
}

\section{RESUMEN}

La caries dental representa un problema crónico de alta prevalencia a nivel mundial. Es considerada como un proceso complejo en comparación con otras enfermedades, pues a diferencia de otras patologías, la caries no se puede definir como la presencia de un microorganismo específico, ya que intervienen diversos factores, entre ellos la genética, cuyo rol como factor etiológico ha sido relevante en la actualidad. Debido a que dentro de la cavidad oral los principales mecanismos de defensa frente a microorganismos cariogénicos se encuentran presentes en saliva y fluido crevicular gingival, muchos de los estudios han tratado de conocer la asociación entre variantes en genes de la respuesta inmune y caries dental. Además de los genes relacionados con la respuesta inmune, también se han incluido los implicados en el proceso de amelogénesis, pues se ha reconocido que variantes en la estructura del esmalte conllevan a una mayor susceptibilidad a caries. En la presente revisión se pretende mostrar los resultados obtenidos en diversos estudios sobre genes y su participación en el desarrollo de caries. Para cumplir con ello, se realizó una búsqueda bibliográfica en las bases de datos PubMed, Dialnet, Redalyc y Google Académico, también fueron consultados libros de odontología.

Palabras clave: Caries dental, caries y genes asociados, genes y amelogénesis, genes y saliva, microorganismos con actividad cariogénica.

\section{ABSTRACT}

Dental caries represents a chronic problem with a high prevalence worldwide. It is considered a complex process compared to other diseases, because unlike other pathological processes, caries cannot be defined as the presence of a specific microorganism, different factors are involved, including genetics. The role that genetics plays as an etiological factor has been a relevant issue in recent years. Because within the oral cavity the main defense mechanisms against cariogenic microorganisms are present in saliva and crevicular fluid, many of the studies have sought to know the association between genetic variants of the immune response and dental caries. In addition to the genes related to the immune response, among the candidate genes that have also been studied are those involved in the amelogenesis process, since it has been recognized that variants in the structure of enamel lead to greater susceptibility to cavities. This article aims to present the results obtained in various studies, on genes and their participation in the development of cavities. To comply with this, a bibliographic search was carried out in the databases PubMed, Dialnet, Redalyc and Google Scholar, and dentistry books were also consulted.

Keywords: Dental caries, caries and associated genes, genes and amelogenesis, genes and saliva, microorganisms with cariogenic activity.

principales, las bacterias presentes en la biopelícula dental, la presencia de carbohidratos fermentables y la superficie dentaria. ${ }^{1}$ Esta enfermedad representa un problema de salud a nivel mundial. Es una de las enfer-

La caries dental es una enfermedad de origen multifactorial, que se produce por la interacción de tres factores

\footnotetext{
* Egresada de la Licenciatura en Cirujano Dentista. Centro Universitario de Ciencias de la Salud.

‡ Instituto de Investigación en Odontología, Departamento de Clínicas Odontológicas Integrales, Centro Universitario de Ciencias de la Salud.

$\S$ Departamento de Ciencias de la Salud. Centro Universitario de los Altos.
}

Universidad de Guadalajara. México.

Recibido: 12 de agosto de 2021. Aceptado: 07 de octubre de 2021.

Citar como: Orozco MKF, Fuentes LMG, Gutiérrez AM, Mariaud SRP. Genes asociados al proceso carioso. Rev Mex Periodontol. 2021; 12 (1-3): 18-29. https:// dx.doi.org/10.35366/102955 
medades bucodentales más frecuentes que afecta ambas denticiones, se estima que alrededor de 2,300 millones de personas padecen caries en dientes permanentes, mientras que 530 millones de niños sufren de caries que afecta su dentición temporal. ${ }^{2}$

El proceso carioso inicia con la formación de una película de proteínas que recubre la superficie dentaria, la cual se caracteriza por tener una consistencia suave y que no es visible a simple vista, en ella se albergan varios microorganismos de la flora bucal. A esta biopelícula se adhieren bacterias cariogénicas que, ante la presencia de carbohidratos fermentables, producen ácido láctico que comienza a erosionar la superficie del esmalte. Sin embargo, debido a la presencia de iones de fosfato y calcio en saliva, la superficie dentaria se remineraliza constantemente. ${ }^{3}$
Cuando el ácido se mantiene durante un tiempo prolongado en contacto con la superficie dentaria, ocasiona la desmineralización subsuperficial de minerales del esmalte. Esta pérdida de minerales inicia con la formación de una mancha blanca, que tras su progresión ocasiona discontinuidad del esmalte hasta formar una cavidad. Se ha demostrado que el factor principal que influye en el inicio y la progresión de la lesión cariosa es el tiempo de retención de carbohidratos fermentables en la cavidad oral. La retención por un tiempo prolongado permite que las bacterias orales transformen los carbohidratos complejos en simples. ${ }^{3}$

Además de los tres factores principales mencionados previamente, hay otros que contribuyen a aumentar o disminuir la velocidad del proceso carioso, como hábitos

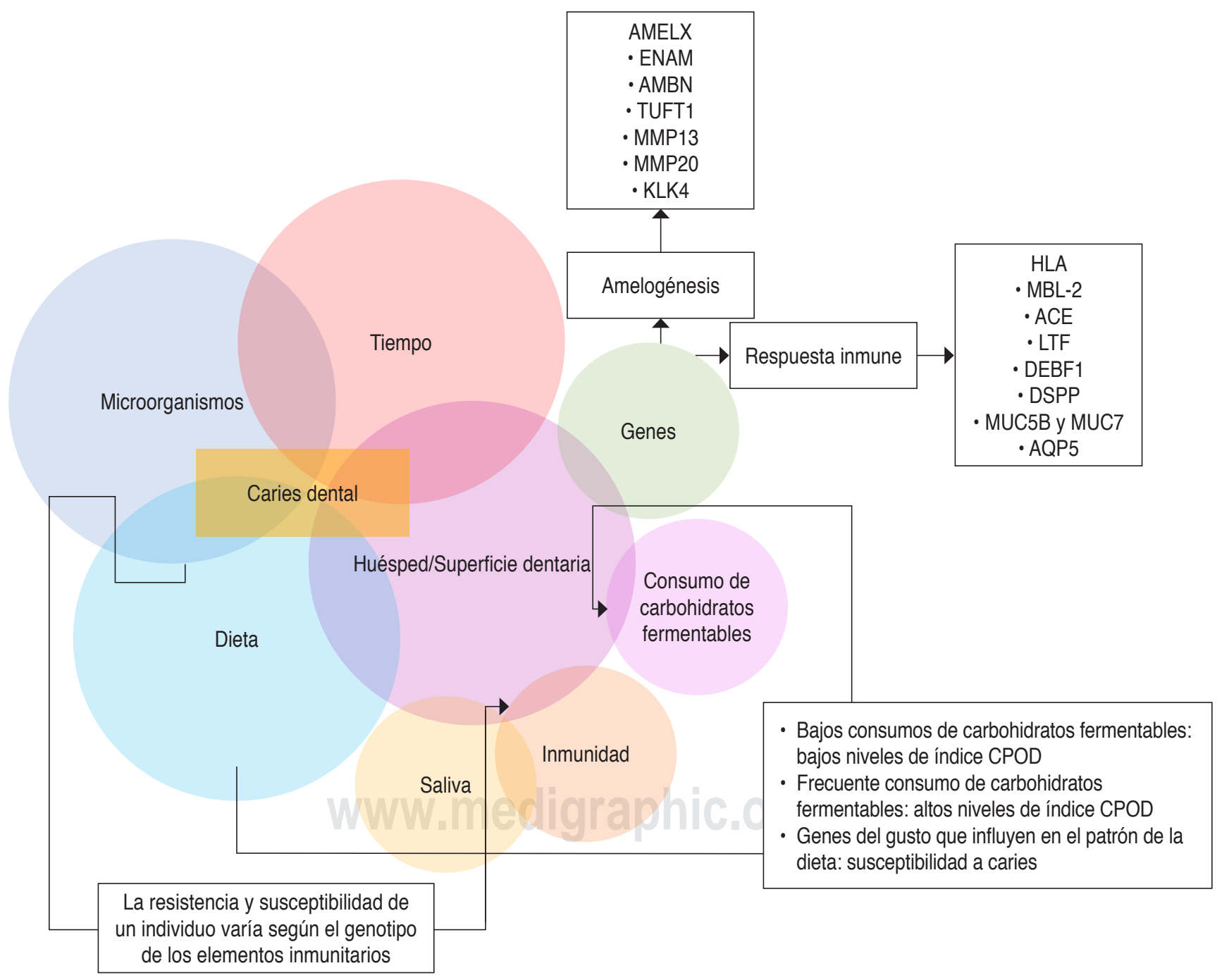

Figura 1: Diagrama de Venn que muestra la interacción de los factores genéticos con la caries dental. Modificado de: Opal S et al. ${ }^{10}$ 
de higiene oral, características anatómicas de la superficie dentaria, hábitos alimenticios, calidad y cantidad de saliva, entre otros. ${ }^{3}$ Además de los factores extrínsecos que contribuyen a la formación de caries dental, conocer el impacto del factor genético con relación al desarrollo de caries ha sido uno de los principales objetivos de diversos estudios. Considerada la alta concordancia y heredabilidad en gemelos, se ha comprobado que además de la influencia de los factores ambientales, genéticamente intervienen varios factores en la aparición y gravedad de la caries dental. ${ }^{4}$

Por otro lado, también se ha observado que algunas personas con bajo consumo de alimentos y bebidas azucaradas y que tienen una higiene bucal buena, aun así presentan caries dental a lo largo de su vida, por lo que se sugiere que la genética juega un papel importante en la aparición de caries. ${ }^{5}$ A continuación, en la Figura 1 se muestra la interacción de los factores genéticos con la caries dental.

\section{Caries dental}

La caries dental anteriormente se describía como un proceso patológico, posterupción, localizado y generado como producto de la desmineralización de los tejidos duros del diente, ocasionado por la producción ácida bacteriana, que al sobrepasar la remineralización compensatoria por un periodo de tiempo indefinido, concluía con la formación de una cavidad. ${ }^{6}$ Kim y su equipo, en el año 2001, describieron que diariamente se produce una desmineralización mínima de las estructuras dentarias, considerada como normal, la cual es compensada mediante elementos presentes en saliva como calcio, fosfato, fluoruro y otros. ${ }^{7}$ Por su parte Ring, en 1985, afirmó que la única manera de tener una dentición intacta de lesiones cariosas se logra manteniendo la homeostasis entre la desmineralización y la remineralización. ${ }^{6}$ Actualmente, se conoce que esta enfermedad surge como resultado de un desbalance ecológico de la biopelícula, donde predominan bacterias acidogénicas y acidúricas, éstas provocan la aparición y evolución de la lesión cariosa. ${ }^{8}$

\section{Origen e inicio del proceso carioso}

La formación de una lesión cariosa implica tres etapas. La primera consiste en la unión inicial del microorganismo al esmalte dental, lo que da inicio a la colonización microbiana. La segunda comprende la acumulación y la formación de un ecosistema bien organizado (biofilm o biopelícula dental). La tercera es la acumulación y formación de la biopelícula permiten el metabolismo bacteriano, que da como resultado la formación de ácidos que ocasionan la desmineralización de la superficie, lo que corresponde a la última etapa del proceso fisiopatológico de la caries, cuando el proceso de desmineralización continúa, da lugar a la formación de una lesión cavitada. ${ }^{9-11}$ Para que pueda iniciar el proceso de formación de caries, debe haber una interacción entre diversos factores, entre los que podemos mencionar están los microorganismos cariogénicos, dieta, tiempo, superficie del diente, saliva y el factor genético. ${ }^{12}$

La formación de ácidos resulta del metabolismo de los microorganismos cariogénicos. El producto más importante es el ácido láctico, que en grandes concentraciones ocasiona la desmineralización. La presencia de este ácido provoca la liberación de iones de hidrógeno $(\mathrm{H})$ y disminución del $\mathrm{pH}$, los hidrógenos se dispersan hacia el esmalte, ahí éstos reaccionan con iones de fosfato $\left(\mathrm{PO}_{4}^{3}\right)$ y un grupo hidroxilo $\left(\mathrm{OH}^{-}\right)$, formando fosfatos primarios $\left(\mathrm{HPO}_{4}{ }^{2}\right)$, fosfatos secundarios $\left(\mathrm{H}_{2} \mathrm{PO}_{4}{ }^{1}\right)$, ácido fosfórico $\left(\mathrm{H}_{3} \mathrm{PO}_{4}\right)$ y agua $\left(\mathrm{H}_{2} \mathrm{O}\right)$. Esto ocasiona la disminución de los iones de fosfato $\left(\mathrm{PO}_{4}{ }^{3}\right)$ y grupos hidroxilo $\left(\mathrm{OH}^{-}\right)$de los cristales de hidroxiapatita del esmalte, produciendo la desmineralización de la superficie. Una vez que el pH del medio vuelve a neutralizarse, ocurre el proceso de remineralización, que se produce por la disminución de concentración de hidrógeno, y la reconstrucción de los prismas que perdieron los iones de fosfato $\left(\mathrm{PO}_{4}{ }^{3}\right)$, grupos hidroxilo $\left(\mathrm{OH}^{-}\right)$e iones de calcio $\left(\mathrm{Ca}^{2}\right)$ durante la desmineralización. Cuando hay presencia de iones de flúor $(F)$ en el medio oral, éstos desplazan los grupos hidroxilo $\left(\mathrm{OH}^{-}\right)$para formar cristales de hidroxifluorapatita y fluorapatita, haciendo más resistente la superficie del esmalte a la desmineralización. ${ }^{13}$

El proceso carioso implica un constante estado de desmineralización-remineralización, cuando ocurre un desequilibrio, conlleva a la desmineralización del esmalte. ${ }^{12}$ A continuación, en la Figura 2, se ilustra el proceso de desmineralización y remineralización.

La lesión cariosa inicia con cambios histológicos, que no son perceptibles a simple vista, periodo en el cual la caries se define como lesión incipiente. Ésta se observa como una zona de opacidad, ya que la desmineralización es subsuperficial, por lo que a simple vista la superficie dentaria parece tener un aspecto relativamente intacto; sin embargo, al microscopio electrónico se observa una superficie más porosa en comparación con el esmalte sano. ${ }^{14,15}$ Tras estos cambios histológicos en el esmalte y la permanencia del metabolismo bacteriano, el proceso de desmineralización se dirige hacia la unión amelodentinaria y/o dentro de la dentina, hasta la formación de una lesión visiblemente evidente, caracterizada por la formación de una cavidad. ${ }^{16}$ 


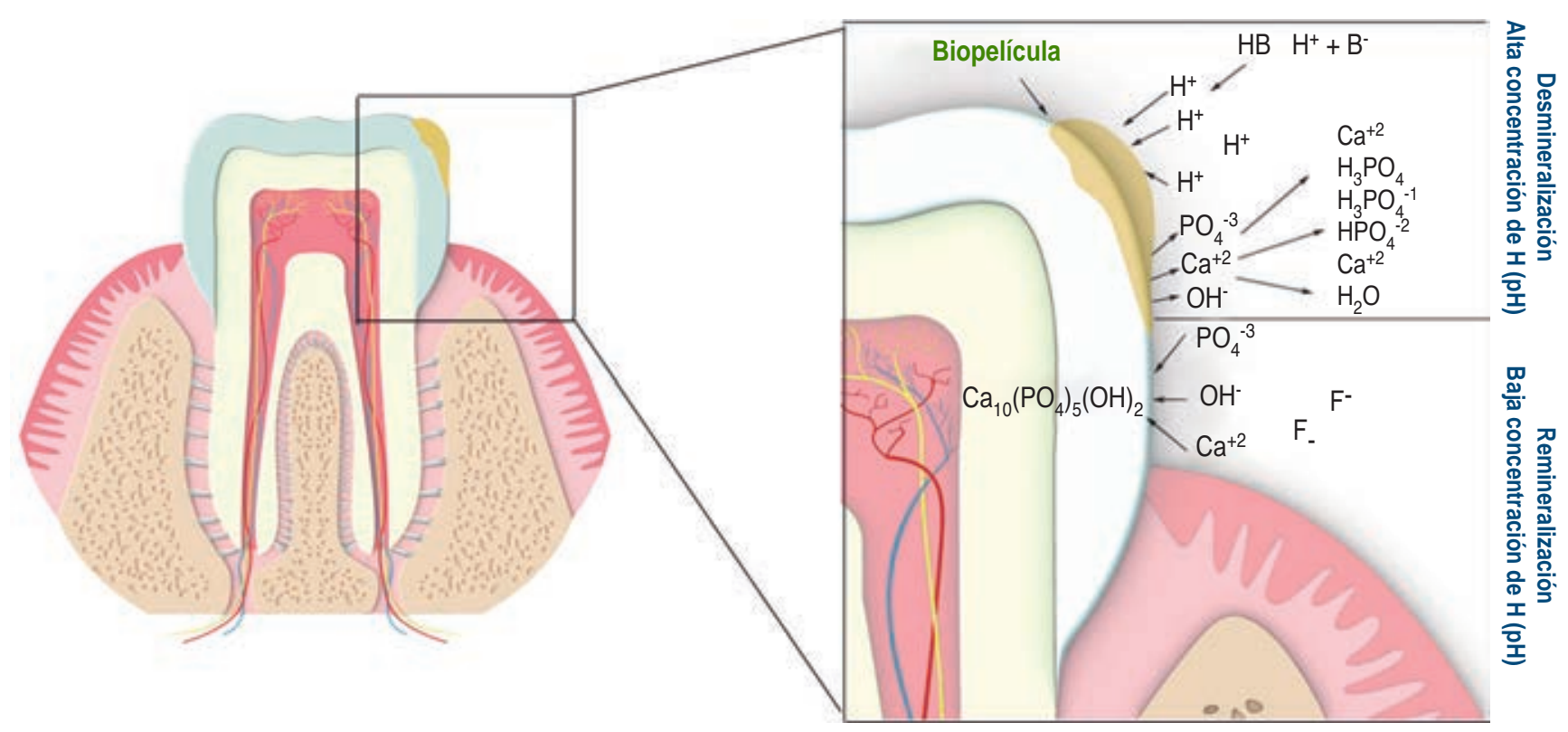

Figura 2: Ilustración del proceso de desmineralización y remineralización del tejido dentario.

Fuente propia.

\section{Participación del proceso inmunológico en la caries}

Frente a una lesión cariosa, el principal mecanismo de defensa del huésped está presente en la saliva y sus componentes. En el caso de lesiones cariosas con cercanía al margen gingival, existe una segunda línea de defensa que se asocia a los componentes del fluido crevicular gingival que provienen de la circulación sistémica. ${ }^{17,18}$

Los componentes salivales juegan un rol importante frente a la colonización por microorganismos cariogénicos, la saliva tiene diversos mecanismos para la prevención de caries, tanto el lavado mecánico, como la función antimicrobiana de remineralización y de regulación del pH, dichos mecanismos son llevados a cabo por los componentes salivales. La saliva es un fluido complejo, formado principalmente de secreciones de las glándulas salivales menores y mayores, además de una serie de componentes de origen no salival como fluido crevicular gingival, células sanguíneas, bacterias y productos bacterianos, células epiteliales descamadas y secreciones bronquiales. ${ }^{18}$

En la saliva están presentes más de 3,400 proteínas y péptidos que forman parte normal de su contenido. Dentro de las proteínas más abundantes se encuentran la amilasa salival, proteínas ricas en prolina, cistatinas, mucinas, estaterinas, histatinas, lisozimas y defensinas. Las proteínas y péptidos salivales tienen diferentes funciones en relación a la microbiota oral. Dichas funciones pueden variar o incluso ser opuestas, ya que pueden ser fuente de nutrientes para los microorganismos o tener actividad antimicrobiana. ${ }^{18}$

\section{Genética y caries}

El inicio y la progresión del proceso carioso se ve influenciado por el equilibrio entre factores protectores y patológicos. Los primeros impulsan el proceso carioso hacia la remineralización y la detección de lesiones (componentes salivales, buenos hábitos de higiene y productos que contienen fluoruro). Los segundos conducen el proceso carioso a la desmineralización (bacterias cariogénicas, la frecuente ingesta de carbohidratos fermentables y disfunción salival). ${ }^{12}$ En algunas ocasiones, individuos que poseen los mismos factores de protección y patológicos, con una higiene oral similar, presentan diferentes patrones de afectación por caries dental. En estos casos, se considera que el factor genético juega un papel importante, aunado a resistencia o susceptibilidad a caries.

En la última década se ha visto un aumento de estudios que se han centrado en encontrar la relación entre los factores genéticos y el riesgo a desarrollar caries. Vieira y su equipo afirman que hay dos maneras principales de estudiar un rasgo tan complejo como lo es la caries; la primera es investigar aquellos genes que son candidatos y llevan una relación directa con el tejido dental, y la segunda es evaluando todo el genoma. Los genes candidatos del proceso carioso pueden agruparse en categorías, las principales incluyen genes que participan en la formación del esmalte, la respuesta inmune y relacionados con la saliva, sin embargo, el grupo de genes candidatos más estudiados son los que se ven implicados en la amelogénesis. ${ }^{19}$ 
Tabla 1: Estudios de asociación entre genes implicados con amelogénesis y caries dental.

\begin{tabular}{|c|c|c|c|}
\hline Gen & Función & Resultados obtenidos & Referencias \\
\hline \multirow[t]{4}{*}{$\begin{array}{l}\text { AMELX } \\
\text { (amelogenina) }\end{array}$} & \multirow{4}{*}{$\begin{array}{l}\text { Involucrada } \\
\text { en la } \\
\text { mineralización } \\
\text { durante el } \\
\text { desarrollo del } \\
\text { esmalte dental }\end{array}$} & $\begin{array}{l}\text { Experiencias altas de caries asociadas con la } \\
\text { presencia de variantes genéticas }\end{array}$ & 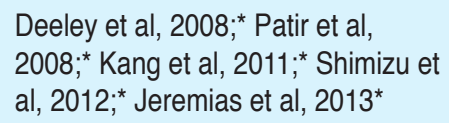 \\
\hline & & $\begin{array}{l}\text { Cambios en la microdureza del esmalte y aumento } \\
\text { de susceptibilidad a caries, asociados con la } \\
\text { presencia de mutaciones y deleciones del gen }\end{array}$ & $\begin{array}{l}\text { Shimizu et al, } 2012 ;{ }^{23} \text { Saha et al, } \\
2015 ;{ }^{24} \text { Ouryouji et al, } 2008 ;{ }^{25} \text { Hu et } \\
\text { al, } 2012^{26}\end{array}$ \\
\hline & & No se encontró evidencia de asociación con caries & 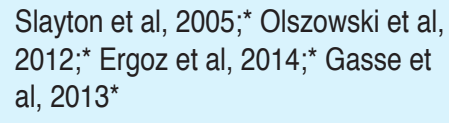 \\
\hline & & $\begin{array}{l}\text { Defectos en el desarrollo del esmalte en dentición } \\
\text { temporal asociados a variantes genéticas podrían ser } \\
\text { consideradas como marcadores de caries dental }\end{array}$ & $\begin{array}{l}\text { Gerreth et al, } 2017 .{ }^{27} \text { Gerreth et al., } \\
2018 .{ }^{28}\end{array}$ \\
\hline \multirow[t]{4}{*}{$\begin{array}{l}\text { ENAM } \\
\text { (enamelina) }\end{array}$} & \multirow{4}{*}{$\begin{array}{l}\text { Involucrada } \\
\text { en la } \\
\text { mineralización } \\
\text { y organización } \\
\text { estructural del } \\
\text { esmalte }\end{array}$} & $\begin{array}{l}\text { Experiencias altas de caries asociadas con la } \\
\text { presencia de variantes genéticas }\end{array}$ & $\begin{array}{l}\text { Patir et al, 2008;* Shimizu et al, } \\
\text { 2012;* Jeremias et al, 2013* }\end{array}$ \\
\hline & & $\begin{array}{l}\text { Cambios en la microdureza del esmalte y aumento } \\
\text { de susceptibilidad a caries, asociados con la } \\
\text { presencia de variantes genéticas }\end{array}$ & Chaussain et al, $2014^{29}$ \\
\hline & & No se encontró evidencia de asociación con caries & $\begin{array}{l}\text { Slayton et al, 2005;" Deeley et al, } \\
\text { 2008;* Olszowski et al, 2012;" Wang } \\
\text { et al, 2012;" Ergoz et al, 2014* }\end{array}$ \\
\hline & & $\begin{array}{l}\text { El genotipo GG ha demostrado conferir protección al } \\
\text { huésped contra caries }\end{array}$ & Abbasoglu et al, $2015^{30}$ \\
\hline \multirow[t]{3}{*}{$\begin{array}{l}\text { AMBN } \\
\text { (ameloblastina) }\end{array}$} & \multirow{3}{*}{$\begin{array}{l}\text { Involucrada en } \\
\text { la formación y } \\
\text { mineralización } \\
\text { de la matriz del } \\
\text { esmalte }\end{array}$} & $\begin{array}{l}\text { Experiencias altas de caries asociadas con la } \\
\text { presencia de variantes genéticas }\end{array}$ & $\begin{array}{l}\text { Patir et al, 2008;* Shimizu et al, } \\
2012 ;{ }^{*} \text { Ergoz et al, 2014* }\end{array}$ \\
\hline & & No se encontró evidencia de asociación con caries & $\begin{array}{l}\text { Slayton et al, 2005; ' Deeley et al, } \\
2008 ;^{*} \text { Jeremias et al, } 2013^{\star}\end{array}$ \\
\hline & & $\begin{array}{l}\text { Defectos en el desarrollo del esmalte en dentición } \\
\text { temporal asociados a variantes genéticas podrían ser } \\
\text { consideradas como marcadores de caries dental }\end{array}$ & $\begin{array}{l}\text { Gerreth et al, } 2017,{ }^{27} \text { Gerreth et al, } \\
2018^{28}\end{array}$ \\
\hline \multirow[t]{5}{*}{$\begin{array}{l}\text { TUFT1 } \\
\text { (tuftelina) }\end{array}$} & \multirow{5}{*}{$\begin{array}{l}\text { Proteína } \\
\text { involucrada } \\
\text { en la } \\
\text { mineralización } \\
\text { dental y } \\
\text { desarrollo } \\
\text { de tejidos } \\
\text { blandos no } \\
\text { mineralizados }\end{array}$} & $\begin{array}{l}\text { Experiencias altas de caries asociadas con la } \\
\text { presencia de variantes genéticas }\end{array}$ & $\begin{array}{l}\text { Slayton et al, } 2005 ;{ }^{*} \text { Deeley et al, } \\
2008 ; ;^{*} \text { Patir et al, } 2008^{*}\end{array}$ \\
\hline & & $\begin{array}{l}\text { Esmalte más susceptible a la desmineralización, } \\
\text { asociado con la presencia de variantes genéticas }\end{array}$ & $\begin{array}{l}\text { Slayton et al, 2005;" Shimizu et al, } \\
2013^{23}\end{array}$ \\
\hline & & $\begin{array}{l}\text { Variantes genéticas podrían ser consideradas como } \\
\text { marcadores genéticos de caries dental }\end{array}$ & $\begin{array}{l}\text { Slayton et al, 2005, }{ }^{*} \text { Shimizu et al, } \\
2012^{23}\end{array}$ \\
\hline & & No se encontró evidencia de asociación con caries & $\begin{array}{l}\text { Wang et al, 2012;* Ergoz et al, } \\
2014 ;^{*} \text { Jeremias et al, } 2013^{*}\end{array}$ \\
\hline & & $\begin{array}{l}\text { El genotipo GG del gen ha demostrado conferir } \\
\text { protección al huésped contra las caries }\end{array}$ & Abbasoglu et al, $2015^{30}$ \\
\hline \multirow{2}{*}{$\begin{array}{l}\text { TFIP11 } \\
\text { (proteína } 11 \text { que } \\
\text { interactúa con } \\
\text { tuftelina) }\end{array}$} & $\begin{array}{l}\text { Componente } \\
\text { proteico que } \\
\text { participa en }\end{array}$ & $\begin{array}{l}\text { Asociado con el inicio del proceso carioso y altas } \\
\text { experiencias de caries dental }\end{array}$ & $\begin{array}{l}\text { Shimizu et al, 2012;23 Jeremias et } \\
\text { al, } 2013^{\star}\end{array}$ \\
\hline & $\begin{array}{l}\text { el proceso } \\
\text { de splicing } \\
\text { durante la } \\
\text { transcripción } \\
\text { de ADN a ARN }\end{array}$ & No se encontró evidencia de asociación con caries & $\begin{array}{l}\text { Slayton et al, 2005;" Deeley et al, } \\
\text { 2008; }{ }^{*} \text { Patir et al, 2008; }{ }^{*} \text { Shimizu et } \\
\text { al, 2012; }{ }^{23} \text { Ergoz et al, 2014* }\end{array}$ \\
\hline
\end{tabular}


Continúa Tabla 1: Estudios de asociación entre genes implicados con amelogénesis y caries dental.

\begin{tabular}{|c|c|c|c|}
\hline Gen & Función & Resultados obtenidos & Referencias \\
\hline $\begin{array}{l}\text { MMP13 } \\
\text { (metaloproteinasa } \\
\text { de la matriz 13) }\end{array}$ & $\begin{array}{l}\text { Encargado de } \\
\text { la osificación } \\
\text { endocondral } \\
\text { y la } \\
\text { remodelación } \\
\text { ósea }\end{array}$ & $\begin{array}{l}\text { Experiencias bajas de caries asociadas con la } \\
\text { presencia de variantes genéticas }\end{array}$ & Tannure et al, 2012* \\
\hline \multirow{2}{*}{$\begin{array}{l}\text { MMPg } \\
\text { (metaloproteinasa } \\
\text { de la matriz 9) }\end{array}$} & \multirow{2}{*}{$\begin{array}{l}\text { Involucrada en } \\
\text { la degradación } \\
\text { de la matriz } \\
\text { extracelular } \\
\text { en algunos } \\
\text { procesos } \\
\text { fisiológicos }\end{array}$} & $\begin{array}{l}\text { Asociado con el desarrollo de lesiones de mancha } \\
\text { blanca y caries de la infancia temprana }\end{array}$ & Antunes et al, $2015^{31}$ \\
\hline & & No se encontró evidencia de asociación con caries & Tannure et al, 2012* \\
\hline \multirow[t]{4}{*}{$\begin{array}{l}\text { MMP20 } \\
\text { (metaloproteinasa } \\
\text { de la matriz 20) }\end{array}$} & \multirow[t]{4}{*}{$\begin{array}{l}\text { Degradación } \\
\text { de } \\
\text { amelogenina }\end{array}$} & $\begin{array}{l}\text { Experiencias altas de caries asociadas con la } \\
\text { presencia de variantes genéticas, en personas con } \\
\text { una higiene oral deficiente }\end{array}$ & Tannure et al, 2012* \\
\hline & & $\begin{array}{l}\text { Asociado con el desarrollo de lesiones de mancha } \\
\text { blanca y caries de la infancia temprana }\end{array}$ & Antunes et al, $2015^{31}$ \\
\hline & & $\begin{array}{l}\text { La variante rs } 1784418 \text { ha demostrado conferir } \\
\text { protección al huésped contra caries dental }\end{array}$ & Filho et al, $2016^{32}$ \\
\hline & & No se encontró evidencia de asociación con caries & Wang et al, $2012^{33}$ \\
\hline \multirow{3}{*}{$\begin{array}{l}\text { KLK4 } \\
\text { (peptidasa } 4 \\
\text { relacionada con } \\
\text { calicreína) }\end{array}$} & \multirow{3}{*}{$\begin{array}{l}\text { Involucrada en } \\
\text { la degradación } \\
\text { de las } \\
\text { proteínas del } \\
\text { esmalte }\end{array}$} & $\begin{array}{l}\text { Asociado con protección al huésped en presencia de } \\
\text { la variante rs } 198968\end{array}$ & Wang et al, $2012^{33}$ \\
\hline & & $\begin{array}{l}\text { Variantes genéticas podrían ser consideradas como } \\
\text { marcadores genéticos de caries dental }\end{array}$ & Gerreth et al, $2017^{27}$ \\
\hline & & $\begin{array}{l}\text { Los genotipos AG y GG del gen han demostrado } \\
\text { conferir protección al huésped contra caries }\end{array}$ & Abbasoglu et al, $2015^{30}$ \\
\hline
\end{tabular}

Modificado de Viera et al., 2014. ${ }^{19}{ }^{*}$ Referencia citada por Vieira et al., $2014^{19}$ en Caries: Review of Human Genetics Research.

\section{Genes que participan en la amelogénesis y su relación con la caries dental}

La amelogénesis puede verse afectada por diversos factores externos como fiebre, desnutrición, xenobióticos, contaminantes y factores internos, como el componente genético. ${ }^{20}$ Las variantes en los genes que codifican para las proteínas de la matriz del esmalte pueden llegar a ocasionar malformaciones o modificaciones. Los trastornos provocados durante la etapa secretora de la amelogénesis se ven relacionados con cambios estructurales como esmalte hipoplásico o patológicamente delgado. Mientras que trastornos presentados durante la etapa de maduración y transición se han visto relacionados con un esmalte hipomineralizado o patológicamente blando. ${ }^{21}$ Por otra parte, Slayton planteó qué variantes presentes en genes que participan en la formación del esmalte influyen significativamente en la adherencia bacteriana, así como también en la resistencia frente a ácidos bacterianos. ${ }^{22}$

A continuación, en la Tabla 1, se muestran los hallazgos encontrados por algunos investigadores acerca de la asociación entre la presencia de variantes en genes que codifican para proteínas de la matriz del esmalte y su relación con caries dental.

\section{Caries dental y genes de la respuesta inmune}

Se conoce que el desarrollo de la caries dental se ve influenciado tanto por factores genéticos como factores ambientales, sin embargo, se ha observado que algunos factores ambientales pueden ser potencialmente más cariogénicos para algunas personas que para otras. ${ }^{34} \mathrm{Ade}-$ más, es conocido que el Streptococcus mutans, principal 
Tabla 2: Estudios de asociación entre genes implicados con respuesta inmune y caries.

\begin{tabular}{|c|c|c|c|}
\hline Gen & Función & Resultados obtenidos & Referencias \\
\hline \multirow[t]{3}{*}{$\begin{array}{l}\text { HLA } \\
\text { (antígeno } \\
\text { leucocitario } \\
\text { humano) }\end{array}$} & $\begin{array}{l}\text { Participa en el sistema } \\
\text { inmunológico, encargado de } \\
\text { la presentación de péptidos } \\
\text { derivados de proteínas } \\
\text { extracelulares }\end{array}$ & $\begin{array}{l}\text { Asociado con experiencia de caries, } \\
\text { relacionado con alteraciones en el } \\
\text { mecanismo de acción, en presencia de } \\
\text { variantes genéticas }\end{array}$ & $\begin{array}{l}\text { Lehner et al, 1981; }{ }^{*} \text { Altun et al, } \\
\text { 2008; } \text { Bagherian et al, 2008;" } \\
\text { Valarini et al, 2012;" Ozawa et al, } \\
2001^{41}\end{array}$ \\
\hline & & Predisposición a caries & $\begin{array}{l}\text { Mariani et al, 1994; }{ }^{42} \text { Tighe et al, } \\
1992^{43}\end{array}$ \\
\hline & & No hay evidencia de asociación con caries & De Vries et al, $1985^{\star}$ \\
\hline \multirow{3}{*}{$\begin{array}{l}\text { MBL2 } \\
\text { (lectina fijadora de } \\
\text { manosa, [proteína } \\
\text { C] 2, soluble) }\end{array}$} & $\begin{array}{l}\text { Participa en el } \\
\text { reconocimiento y unión a } \\
\text { moléculas de manosa y }\end{array}$ & $\begin{array}{l}\text { Experiencias altas de caries asociadas } \\
\text { con la presencia de mutaciones en el gen }\end{array}$ & Wang et al, $2004^{44}$ \\
\hline & $\begin{array}{l}\mathrm{N} \text {-acetilglucosamina en } \\
\text { muchos microorganismos }\end{array}$ & $\begin{array}{l}\text { Experiencias altas y bajas de caries de } \\
\text { acuerdo con la dentición, en presencia } \\
\text { de variantes genéticas }\end{array}$ & Olszowski et al, $2012^{*}$ \\
\hline & & $\begin{array}{l}\text { No se encontró asociación entre caries } \\
\text { de la infancia temprana y el gen }\end{array}$ & Yang et al, $2013^{*}$ \\
\hline \multirow{2}{*}{$\begin{array}{l}\text { ACE } \\
\text { (enzima } \\
\text { convertidora de } \\
\text { angiotensina) }\end{array}$} & $\begin{array}{l}\text { Involucrada en la regulación } \\
\text { de la presión arterial y el } \\
\text { equilibrio de electrolitos }\end{array}$ & $\begin{array}{l}\text { Experiencias altas y bajas de caries } \\
\text { asociadas con la presencia de variantes } \\
\text { genéticas }\end{array}$ & $\begin{array}{l}\text { Wang et al, 2010; } 45 \text { Linhartova et } \\
\text { al, } 2016^{46}\end{array}$ \\
\hline & & $\begin{array}{l}\text { Se considera que el genotipo DD de la } \\
\text { variante ACE I/D le confiere protección } \\
\text { al huésped contra caries dental }\end{array}$ & Olszowski et al, $2015^{47}$ \\
\hline \multirow[t]{3}{*}{$\begin{array}{l}\text { LTF } \\
\text { (lactoferrina) }\end{array}$} & $\begin{array}{l}\text { Desempeñan una actividad } \\
\text { antimicrobiana, antiviral, } \\
\text { antifúngica, antiparasitaria }\end{array}$ & $\begin{array}{l}\text { Experiencias bajas de caries asociadas } \\
\text { a la presencia de variantes genéticas }\end{array}$ & $\begin{array}{l}\text { Fine et al, 2013; }{ }^{*} \text { Abbasoglu et } \\
\text { al, } 2015^{30}\end{array}$ \\
\hline & & $\begin{array}{l}\text { Variantes en este gen han demostrado } \\
\text { conferir protección al huésped }\end{array}$ & $\begin{array}{l}\text { Doetzer et al, 2015; }{ }^{48} \text { Azevedo et } \\
\text { al, 2010* }\end{array}$ \\
\hline & & $\begin{array}{l}\text { No hay evidencia de asociación con } \\
\text { caries }\end{array}$ & $\begin{array}{l}\text { Brancher et al, 2011; }{ }^{*} \text { Volckova } \\
\text { M et al, 201499 }\end{array}$ \\
\hline \multirow[t]{2}{*}{$\begin{array}{l}\text { DEFB1 } \\
\text { (defensina beta 1) }\end{array}$} & $\begin{array}{l}\text { Grupo de péptidos catiónicos } \\
\text { antimicrobianos que } \\
\text { interactúan de manera } \\
\text { electrostática con las }\end{array}$ & $\begin{array}{l}\text { Experiencias altas y bajas de caries } \\
\text { asociadas con la presencia de variantes } \\
\text { genéticas }\end{array}$ & $\begin{array}{l}\text { Weinberg et al, 1998:50 Ozturk et } \\
\text { al, 2010;" Krasone et al, 2013* }\end{array}$ \\
\hline & $\begin{array}{l}\text { bacterias, realizando un } \\
\text { efecto bactericida, antifúngico } \\
\text { y antiviral }\end{array}$ & $\begin{array}{l}\text { No hay evidencia de asociación con } \\
\text { caries }\end{array}$ & Lips et al, $2017^{51}$ \\
\hline \multirow{2}{*}{$\begin{array}{l}\text { DSPP } \\
\text { (sialoproteína } \\
\text { fosfodentinaria) }\end{array}$} & $\begin{array}{l}\text { Participa en la mineralización } \\
\text { dentinaria }\end{array}$ & $\begin{array}{l}\text { Variantes en este gen han demostrado } \\
\text { conferir protección al huésped }\end{array}$ & Wang et al, $2012^{\star}$ \\
\hline & & $\begin{array}{l}\text { Mutaciones en este gen ocasionan } \\
\text { la producción de dentina más suave } \\
\text { y malformada, asociadas con mayor } \\
\text { susceptibilidad a caries }\end{array}$ & Kim et al, $2005^{52}$ \\
\hline
\end{tabular}


Continúa Tabla 2: Estudios de asociación entre genes implicados con respuesta inmune y caries.

\begin{tabular}{|c|c|c|c|}
\hline Gen & Función & Resultados obtenidos & Referencias \\
\hline \multirow[t]{3}{*}{$\begin{array}{l}\text { MUC5B y MUC7 } \\
\text { (mucina 5B y } 7 \text { ) }\end{array}$} & \multirow{3}{*}{$\begin{array}{l}\text { Realizan diversas actividades } \\
\text { de las proteínas incluidas } \\
\text { enzimas, proteínas de } \\
\text { transporte, proteínas } \\
\text { estructurales, hormonas y } \\
\text { receptores }\end{array}$} & $\begin{array}{l}\text { Variantes genéticas ocasionan contenidos } \\
\text { bajos de mucinas MG1 y MG2, asociadas } \\
\text { con altas experiencias de caries }\end{array}$ & $\begin{array}{l}\text { Jodkowska, } 2010{ }^{53} \text { Banderas- } \\
\text { Tarabay et al, } 2002^{54}\end{array}$ \\
\hline & & $\begin{array}{l}\text { Variantes genéticas en el gen MUC5 } \\
\text { han demostrado que pueden influir en el } \\
\text { desarrollo de caries }\end{array}$ & Cavallari et al, $2017^{55}$ \\
\hline & & $\begin{array}{l}\text { No se encontró asociación con el gen } \\
\text { MUC7 y caries dental }\end{array}$ & $\begin{array}{l}\text { Buczkowska-Radlinska et al, } \\
2012^{\star}\end{array}$ \\
\hline \multirow[t]{2}{*}{$\begin{array}{l}\text { AQP5 } \\
\text { (aquaporina 5) }\end{array}$} & \multirow{2}{*}{$\begin{array}{l}\text { Producción de lágrimas, } \\
\text { secreciones pulmonares y } \\
\text { saliva }\end{array}$} & $\begin{array}{l}\text { Variantes en este gen han demostrado } \\
\text { conferir protección al huésped }\end{array}$ & Wang et al, $2012^{*}$ \\
\hline & & $\begin{array}{l}\text { Deleciones en el gen ocasionan } \\
\text { disminución en el flujo salival, asociado } \\
\text { con altas experiencias de caries }\end{array}$ & Culp et al, $2005^{56}$ \\
\hline $\begin{array}{l}\text { PRH2/PR } \\
\text { (proteína rica en } \\
\text { prolina subfamilia } \\
\text { 2) }\end{array}$ & $\begin{array}{l}\text { Grupo de proteínas } \\
\text { que promueven la } \\
\text { remineralización dentaria, } \\
\text { formación de la película } \\
\text { adquirida, lubricación } \\
\text { de la mucosa y acción } \\
\text { antibacteriana }\end{array}$ & $\begin{array}{l}\text { Gen asociado con susceptibilidad a } \\
\text { caries }\end{array}$ & Yu et al, $1986^{57}$ \\
\hline \multirow{3}{*}{$\begin{array}{l}\text { PRH1 } \\
\text { (proteína rica en } \\
\text { prolina HaellI } \\
\text { subfamilia 1) }\end{array}$} & \multirow[t]{3}{*}{$\begin{array}{l}\text { Proporciona protección a la } \\
\text { superficie dentaria }\end{array}$} & $\begin{array}{l}\text { Gen asociado con susceptibilidad a } \\
\text { caries dental }\end{array}$ & Yu et al, $1986^{57}$ \\
\hline & & $\begin{array}{l}\text { No se encontró asociación con caries } \\
\text { dental }\end{array}$ & $\begin{array}{l}\text { Anderson \& Mandel, } 1982,58 \\
\text { Anderson et al, } 1982^{59}\end{array}$ \\
\hline & & $\begin{array}{l}\text { En personas con un índice } \mathrm{CPOD} \geq 10 \\
\text { se observó una reducción significativa } \\
\text { de la isoforma PRP-1 de este gen }\end{array}$ & Banderas-Tarabay et al, $2002^{*}$ \\
\hline $\begin{array}{l}\text { PRB2 } \\
\text { (proteína rica } \\
\text { en prolina BstNI } \\
\text { subfamilia 2) }\end{array}$ & $\begin{array}{l}\text { Grupo de glicoproteínas } \\
\text { salivales que proporciona } \\
\text { protección a la superficie } \\
\text { dentaria }\end{array}$ & $\begin{array}{l}\text { No se encontró asociación con caries } \\
\text { dental }\end{array}$ & Anderson et al, $1982^{59}$ \\
\hline $\begin{array}{l}\text { PRB1 } \\
\text { (proteína rica } \\
\text { en prolina BstNI } \\
\text { subfamilia 1) }\end{array}$ & $\begin{array}{l}\text { Grupo de glicoproteínas } \\
\text { salivales que proporciona } \\
\text { protección a la superficie } \\
\text { dentaria }\end{array}$ & $\begin{array}{l}\text { No se encontró asociación con caries } \\
\text { dental }\end{array}$ & Anderson et al, $1982^{59}$ \\
\hline $\begin{array}{l}\text { MASP2 } \\
\text { (serina proteasa } 2 \\
\text { asociada a MBL) }\end{array}$ & $\begin{array}{l}\text { Peptidasa con efecto } \\
\text { bacteriostático, que se une } \\
\text { a los polisacáridos RA y R2 } \\
\text { expresados por algunas } \\
\text { enterobacterias }\end{array}$ & $\begin{array}{l}\text { No se encontró asociación entre el gen y } \\
\text { caries dental }\end{array}$ & Olszowski et al, $2012^{60}$ \\
\hline $\begin{array}{l}\text { CA6 } \\
\text { (anhídrido } \\
\text { carbónico 6) }\end{array}$ & $\begin{array}{l}\text { Participa en la hidratación } \\
\text { reversible del dióxido de } \\
\text { carbono, aún se desconoce } \\
\text { su función en saliva }\end{array}$ & $\begin{array}{l}\text { El haplotipo ACA del gen CA6 ha } \\
\text { demostrado conferir susceptibilidad al } \\
\text { huésped, para caries dental }\end{array}$ & Li et al, $2015^{61}$ \\
\hline $\begin{array}{l}\text { ALOX15 } \\
\text { (15-lipooxigenasa) }\end{array}$ & $\begin{array}{l}\text { Los productos enzimáticos } \\
\text { y la enzima para la que } \\
\text { codifica el gen regulan la } \\
\text { inflamación y la inmunidad }\end{array}$ & $\begin{array}{l}\text { El genotipo TT del gen ha sido } \\
\text { identificado como factor de riesgo para } \\
\text { el desarrollo de caries en la infancia } \\
\text { temprana }\end{array}$ & Abbasoglu et al, $2015^{30}$ \\
\hline
\end{tabular}


Continúa Tabla 2: Estudios de asociación entre genes implicados con respuesta inmune y caries.

\begin{tabular}{|c|c|c|c|}
\hline Gen & Función & Resultados obtenidos & Referencias \\
\hline $\begin{array}{l}\text { VDR-Taq } 1 \\
\text { (receptor de } \\
\text { vitamina D Taq 1) }\end{array}$ & $\begin{array}{l}\text { Receptor de vitamina D y } \\
\text { también está involucrado } \\
\text { en el metabolismo mineral, } \\
\text { regula una variedad de } \\
\text { vías metabólicas, como las } \\
\text { involucradas en la respuesta } \\
\text { inmune y el cáncer }\end{array}$ & $\begin{array}{l}\text { El alelo T ha sido considerado como } \\
\text { determinante genético de riesgo para el } \\
\text { desarrollo de caries }\end{array}$ & Hu et al, $2015^{62}$ \\
\hline $\begin{array}{l}\text { TIMP1 y TIMP2 } \\
\text { (inhibidor de } \\
\text { metalopeptidasa } \\
\text { 1 y 2) }\end{array}$ & $\begin{array}{l}\text { Inhiben contra la mayoría de } \\
\text { las MMP }\end{array}$ & $\begin{array}{l}\text { No se encontró asociación entre el gen } \\
\text { TIMP1 y TIMP2, con caries dental }\end{array}$ & $\begin{array}{l}\text { Alyousef et al, } 2017 ;{ }^{63} \text { Antunes et } \\
\text { al, } 2015^{31}\end{array}$ \\
\hline $\begin{array}{l}\text { GLUT2 } \\
\text { (transportador de } \\
\text { glucosa) }\end{array}$ & $\begin{array}{l}\text { Media el transporte } \\
\text { bidireccional de la glucosa }\end{array}$ & $\begin{array}{l}\text { Gen asociado con una mayor } \\
\text { susceptibilidad a caries dental }\end{array}$ & $\begin{array}{l}\text { Kulkarni et al, 2013; } 64 \\
\text { Izakovicova Holla et al, } 2015^{65}\end{array}$ \\
\hline \multirow[t]{3}{*}{$\begin{array}{l}\text { TAST1R2 y } \\
\text { TAST1R3 } \\
\text { (receptores de } \\
\text { sabores dulces) }\end{array}$} & Receptor de sabores dulces & $\begin{array}{l}\text { Experiencias moderadas de caries } \\
\text { asociadas al gen TAST1R3 y altas } \\
\text { experiencias de caries en asociación } \\
\text { con el gen TASR1R2 }\end{array}$ & Haznedaroglu et al, $2015^{66}$ \\
\hline & & $\begin{array}{l}\text { Variantes genéticas de TAST1R2 han } \\
\text { demostrado una mayor prevalencia de } \\
\text { caries dental }\end{array}$ & Robino et al, $2015^{67}$ \\
\hline & & $\begin{array}{l}\text { Gen asociado con una mayor } \\
\text { susceptibilidad a caries dental }\end{array}$ & Kulkarni et al, $2013^{64}$ \\
\hline
\end{tabular}

Modificado de Vieira et al., 2014. ${ }^{19}{ }^{*}$ Referencia citada por Vieira et al., $2014^{19}$ en Caries: Review of Human Genetics Research.

microorganismo cariogénico, se encuentra presente en casi todos los individuos, no obstante, los niveles de este microorganismo varían de individuo a individuo, dichas variaciones tienen relación directa con la respuesta inmune del huésped. ${ }^{35}$

Por otra parte, Grigalauskiene afirma que el nivel de riesgo de padecer caries dental, está determinado por el microbioma humano y el sistema inmunológico, que a su vez, este último se ve influenciado por factores ambientales y genéticos. ${ }^{36}$ Por lo que algunos componentes del sistema inmunológico, como los genes del sistema HLA y los genes MBL2 y ACE, han sido objeto de estudio para algunos investigadores, quienes han buscado comprender el papel que juegan estos genes y su asociación con la caries dental.

Además de los genes que participan en la mediación de la respuesta inmune, diversos estudios se han enfocado en encontrar la relación entre las variantes en los componentes salivales y las modificaciones en el flujo salival con la cariogenicidad de la biopelícula, ${ }^{37}$ ya que la saliva presenta componentes que participan en la inmunidad innata y adquirida, interviniendo en la inhibición de la colonización bacteriana, el crecimiento y metabolismo bacteriano. ${ }^{37,38}$ La disminución del flujo salival también influye en la cariogenicidad de la biopelícula, ya que ayuda a eliminar de manera eficiente los microorganismos de la cavidad, ${ }^{39,40}$ por lo que las alteraciones en la composición y flujo salival son de gran interés.

En 2008, Vieira y colegas realizaron una exploración genómica para identificar posibles candidatos para la susceptibilidad a caries, en ella encontraron que las regiones genómicas que podrían considerarse son aquellas que alojan genes relacionados con las propiedades de la saliva. ${ }^{19}$ Los principales componentes salivales que han sido estudiados con mayor frecuencia, a fin de comprender la asociación que tienen con caries dental, son las lisozimas, lactoperoxidasas, aglutininas, inmunoglobulinas, mucinas, lactotransferrinas y defensinas. A continuación, en la Tabla 2, son explicados los hallazgos observados por algunos investigadores con relación a la asociación de variantes presentes en genes que codifican para proteínas salivales y genes relacionados con la respuesta inmune y la caries dental. 
Para la elaboración de esta revisión bibliográfica fueron seleccionados 57 artículos publicados, la mayoría de las investigaciones consideraron dentro de sus criterios de inclusión y exclusión algunos factores de riesgo como la frecuencia del cepillado dental, la ingesta de carbohidratos y la capacidad amortiguadora de la saliva de los participantes. Durante la búsqueda y el análisis se encontraron 32 genes, los que han sido estudiados en múltiples investigaciones con el fin de comprender su relación con la caries dental. Cabe mencionar que los genes que han sido más estudiados son aquellos que están directamente asociados con la formación del esmalte y los componentes salivales.

Los resultados presentados en las Tablas 1 y 2 proporcionan evidencia científica que demuestra que los factores genéticos se ven involucrados con el desarrollo de caries dental. Diversos estudios sugieren que cambios en la secuencia de aminoácidos ocasionados por variantes en genes implicados en el proceso de amelogénesis pueden llegar a afectar la función o disminuir la cantidad de proteínas codificantes, lo que puede repercutir en la función que realizan éstas durante el proceso de formación del esmalte.

Como se mostró en la Tabla 1, encontramos que los hallazgos con los que han sido relacionadas dichas variantes génicas hasta el momento son: cambios en la microdureza, variaciones en el espesor y grado de mineralización del esmalte, condiciones que aumentan la susceptibilidad a la desmineralización y, con ello, el riesgo a caries.

Por otro lado, como se mencionó previamente, la primera línea de defensa del huésped ante la presencia de microorganismos cariogénicos se encuentra presente en la saliva y sus componentes. Éstos corresponden al segundo grupo de genes candidatos, que son presentados en la Tabla 2. De acuerdo con los resultados encontrados, variantes en genes que codifican para las proteínas y péptidos salivales, se han visto relacionadas con una disminución de producción o modificación en el mecanismo de acción de estas proteínas y péptidos. Dichos cambios han sido relacionados con experiencias altas y bajas de caries dental. Además de los genes que corresponden a la primera línea de defensa, también se ha encontrado que algunos genes que participan en la mediación de la respuesta inmune, además de tener relación con enfermedades sistémicas, se han visto relacionados con enfermedades bucodentales, entre ellas, las caries.

Con el análisis de datos se podría afirmar que posiblemente la caries dental no es una enfermedad que se hereda como defecto genético único, sino como resultado de diferentes modificaciones genéticas y la interacción de éstas con los demás factores etiológicos de la enfermedad.
El factor genético de la caries sigue siendo un campo amplio que requiere de más investigación científica, por lo que hasta ahora la evidencia existente es insuficiente para determinar cuál gen o variante genética hace más susceptible al huésped para padecer caries dental.

\section{CONCLUSIONES}

De acuerdo con los datos obtenidos en la presente revisión, se sugiere que aunado a los factores extrínsecos que participan en la enfermedad, existen genes asociados al desarrollo de la caries dental, como los que codifican para proteínas de la matriz del esmalte, que pueden ocasionar malformaciones o modificaciones en la estructura del mismo, lo que conlleva a mayor susceptibilidad al desarrollo de caries, entre los que podemos nombrar a los genes AMELX, ENAM, TUFT1, AMBN, MMP13, MMP20 y KLK4. Así como también genes involucrados en la activación de la respuesta inmune del huésped, como los genes del sistema HLA y los genes MBL2 y ACE, que han sido asociados con la presencia de caries. De igual forma, los genes DEFB1, MUC5B y MUCB7 se han relacionado con mayor susceptibilidad a caries. Sin embargo, también se ha observado que genes que codifican para péptidos y proteínas salivales como es el caso de LTF, DSPP y AQP5, han demostrado conferir protección al huésped contra caries.

Es conveniente realizar más investigaciones acerca de la influencia del factor genético como un importante componente etiológico de la caries, lo que a su vez permitirá comprender más acerca de la etiopatogenia de la enfermedad y ayudará a lograr identificar los grupos de riesgo, lo que podría contribuir a mejorar los mecanismos de prevención, diagnóstico y tratamiento.

\section{REFERENCIAS}

1. Kassebaum N, Bernabé E, Dahiya M, Bhandari B, Murray CJ, Marcenes W. Global burden of untreated caries: a systematic review and metaregression. J Dent Res. 2015; 94 (5): 650-658.

2. Thylstrup A, Fejerskov O. Different concepts of dental caries and their implications. Textbook of clinical cariology. 2nd ed. Royal Tunbridge Wells, UK: Blackwell Munksgaard; 1994. pp. 209-221.

3. Bretz W, Corby P, Hart T, Costa S, Coelho M, Weyant R et al. Dental caries and microbial acid production in twins. Caries Res. 2005; 39 (3): 168-172.

4. Almaguer A, Villagómez J. El papel de la saliva en el ecosistema oral. Composición de la saliva. En: Villagómez J, Soria A. Ecología oral. México: El Manual Moderno; 2017.

5. Gutiérrez J. Fundamentos de ciencias básicas aplicadas a la odontología. Bogotá, Colombia: Editorial Pontificia Universidad Javeriana; 2005.

6. Vieira A, Modesto A, Marazita M. Caries: review of human genetics research. Caries Res. 2014; 48: 491-506.

7. Federación Dental Internacional. El desafío de las enfermedades bucodentales - Una llamada a la acción global. Atlas de Salud 
Bucodental [Internet]. Suiza: FDI World Dental Federation; 2015. Disponible en: https://www.fdiworlddental.org/sites/default/files/ media/documents/book_spreads_oh2_spanish.pdf

8. GBD 2017 Disease and Injury Incidence and Prevalence Collaborators. Global, regional, and national incidence, prevalence, and years lived with disability for 354 diseases and injuries for 195 countries and territories, 1990-2017: a systematic analysis for the Global Burden of Disease Study 2017. Lancet. 2018; 392: 1789-1858.

9. Mathur V, Dhillon J. Dental caries: a disease which needs attention. Indian J Pediatr. 2017; 85 (3): 202-206.

10. Opal S, Garg S, Jain J, Walia I. Genetic factors affecting dental caries risk. Aust Dent J. 2015; 60 (1): 2-11.

11. Piekoszewska-Zietek P, Turska-Szybka A, Olczak-Kowalczyk D. Single nucleotide polymorphism in the aetiology of caries: systematic literature review. Caries Res. 2017; 51 (4): 425-435.

12. Ring ME. Dentistry: an illustrated history. New York: Harry N. Abrams, Inc; 1985.

13. Kim J, Jang K, Lee S, Kim C, Hahn S, García-Godoy F. In vivo rehardening od enamel eroded by cola drink. J Dent Child. 2001; 68: 122-124.

14. Banerjee A, Frencken J, Schwendicke F, Innes N. Contemporary operative caries management: consensus recommendations on minimally invasive caries removal. Br Dent J. 2017; 223 (3): 215-222.

15. Rodríguez A, González O. Fisiopatología de la caries dental. Univ Odontol. 2000; 20 (Supl 1): 56-63.

16. Taubman M, Nash D. The scientific and public health imperative for a vaccine against dental caries. Nat Rev Immunol. 2006; 6 (7): $555-563$.

17. Gómez S, Roa N, Rodríguez A. Inmunología de la caries dental En: Gutiérrez S, editor. Fundamentos de ciencias básicas aplicadas a la odontología. Bogotá: Pontificia Universidad Javeriana; 2006. pp. 170-187.

18. Pitts N, Zero D. White paper on dental caries prevention and management. FDI World Dental Federation [Internet]. 2016 [Consultado 20 Mar 2021]; 1-59. Available in: http://www. fdiworlddental.org/sites/default/ files/media/documents/2016fdi_cpp-white_paper.pdf

19. Vieira A, Marazita M, Goldstein-McHenry T. Genome-wide scan finds suggestive caries loci. J Dent Res. 2008; 87 (5): 435-439.

20. Fejerskov O, Kidd E, Nyvad B, Baelum V (eds). Dental caries. The disease and its clinical management. 2nd ed. Denmark: WileyBlackwell; 2008.

21. Worawongvasu R. A scanning electron microscopic study of enamel surfaces of incipient caries. Ultrastruct Pathol. 2015; 39 (6): 408-412.

22. Bowen W. Dental caries - not just holes in teeth! A perspective. Mol Oral Microbiol. 2015; 31 (3): 228-233.

23. Shimizu T, Ho B, Deeley K, Briseño-Ruiz J, Faraco I, Schupack B et al. Enamel formation genes influence enamel microhardness before and after cariogenic challenge. PLoS One. 2012; 7 (9): e450.

24. Saha R, Sood P, Sandhu M, Diwaker A, Upadhyaye S. Association of amelogenin with high caries experience in indian children. J Clin Pediatr Dent. 2015; 39 (5): 458-461.

25. Ouryouji K, Imamura Y, Fujigaki Y, Oomori Y, Yanagisawa S, Miyazawa $\mathrm{H}$ et al. Analysis of mutations in the amelogenin and the enamelin genes in severe caries in Japanese pediatric patients. Pediatr Dent J. 2008; 18 (2): 79-85.

26. Hu J, Chan H, Simmer S, Seymen F, Richardson A, Hu Y et al. Amelogenesis imperfecta in two families with defined AMELX deletions in ARHGAP6. PLoS One. 2012; 7 (12): e52052.

27. Gerreth K, Zaorska K, Zabel M, Borysewicz-Lewicka M, Nowicki M. Chosen single nucleotide polymorphisms (SNPs) of enamel formation genes and dental caries in a population of Polish children. Adv Clin Exp Med. 2017; 26 (6): 899-905.
28. Gerreth K, Zaorska K, Zabel M, Nowicki M, Borysewicz-Lewicka M. Significance of genetic variations in developmental enamel defects of primary dentition in Polish children. Clin Oral Investig. 2018; 22: 321-329.

29. Chaussain C, Bouazza N, Gasse B, Laffont AG, Opsahl Vital S et al. Dental caries and enamelin haplotype. J Dent Res. 2014; 93 (4): 360-365.

30. Abbasoglu Z, Tanboga I, Küchler E, Deeley K, Weber M, Kaspar C et al. Early childhood caries is associated with genetic variants in enamel formation and immune response genes. Caries Res. 2015; 49: 70-77.

31. Antunes L, Antunes L, Küchler E, Lopes L, Moura A, Bigonha R et al. Analysis of the association between polymorphisms in MMP2, MMP3, MMP9, MMP20, TIMP1, and TIMP2 genes with white spot lesions and early childhood caries. Int J Paediatr Dent. 2015; 26 (4): 310-319.

32. Filho A, Calixto M, Deeley K, Santos N, Rosenblatt A, Vieira A. MMP20 rs1784418 protects certain populations against caries. Caries Res. 2016; 51 (1): 46-51.

33. Wang X, Willing M, Marazita M, Wendell S, Warren J, Broffitt B et al. Genetic and environmental factors associated with dental caries in children: the lowa fluoride study. Caries Res. 2012; 46 (3): 177-184.

34. Shuler C. Inherited risks for susceptibility to dental caries. J Dent Educ. 2001; 65 (10): 1038-1045.

35. Wallengren M, Hamberg K, Ericson D, Nordberg J. Low salivary IgA activity to cell-surface antigens of mutans streptococci related to HLA-DRB1*04. Oral Microbiol Immunol. 2005; 20 (2): 73-81.

36. Grigalauskiene R, Slabsinskiene E, Vasiliauskiene I. Biological approach of dental caries management. Stomatologija. 2015; 17 (4): 107-112.

37. Leone C, Oppenheim F. Physical and chemical aspects of saliva as indicators of risk for dental caries in humans. J Dent Educ. 2001; 65 (10): 1054-1062.

38. Orsi N. The antimicrobial activity of lactoferrin: current status and perspectives. Biometals. 2004; 17 (3): 189-196.

39. Antunes J, Frazao P, Narvai P, Bispo C, Pegoretti T. Spatial analysis to identify differentials in dental needs by area-based measures. Community Dent Oral Epidemiol. 2002; 30 (2): 133-142.

40. Gao X, Jiang S, Koh D, Hsu C. Salivary biomarkers for dental caries. Periodontol 2000. 2015; 70 (1): 128-141.

41. Ozawa Y, Chiba J, Sakamoto S. HLA class II alleles and salivary numbers of mutans streptococci and lactobacilli among young adults in Japan. Oral Microbiol Immunol. 2001; 16 (6): 353-357.

42. Mariani P, Mazzilli M, Margutti G, Lionetti P, Triglione P, Petronzelli $\mathrm{F}$ et al. Coeliac disease, enamel defects and HLA typing. Acta Paediatr. 1994; 83 (12): 1272-1275.

43. Tighe M, Hall M, Barbado M, Cardi E, Welsh K, Ciclitira P. HLA class II alleles associated with celiac disease susceptibility in a southern European population. Tissue Antigens. 1992; 40 (2): 90-97.

44. Wang $H$, Nakamura $K$, Inoue $T$, Yanagihori $H$, Kawakami $Y$, Hashimoto $\mathrm{S}$ et al. Mannose-binding lectin polymorphisms in patients with Behcet's disease. J Dermatol Sci. 2004; 36 (2): 115-117.

45. Wang X, Shaffer J, Weyant R, Cuenco K, DeSensi R, Crout R et al. Genes and their effects on dental caries may differ between primary and permanent dentitions. Caries Res. 2010; 44 (3): 277-284.

46. Linhartova P, Kastovsky J, Bartosova M, Musilova K, Zackova $\mathrm{L}$, Kukletova $\mathrm{M}$ et al. ACE Insertion/Deletion polymorphism associated with caries in permanent but not primary dentition in Czech Children. Caries Res. 2016; 50 (2): 89-96.

47. Olszowski T, Adler G, Janiszewska-Olszowska J, Safranow K, Chlubek D. DD genotype of ACE I/D polymorphism might confer protection against dental caries in polish children. Caries Res. 2015; 49 (4): 390-393. 
48. Doetzer A, Brancher J, Pecharki G, Schlipf N, Werneck R, Mira MT et al. Lactotransferrin gene polymorphism associated with caries experience. Caries Res. 2015; 49 (4): 370-377.

49. Volckova M, Borilova P, Trefna T, Vlazny J, Musilova K, Kukletova $\mathrm{M}$ et al. Lack of association between lactotransferrin polymorphism and dental caries. Caries Res. 2014; 48 (1): 39-44.

50. Weinberg A, Krisanaprakornkit S, Dale B. Epithelial antimicrobial peptides: review and significance for oral applications. Crit Rev Oral Biol Med. 1998; 9 (4): 399-414.

51. Lips A, Antunes L, Antunes L, Abreu J, Barreiros D, Oliveira D et al. Genetic polymorphisms in DEFB1 and miRNA202 are involved in salivary human $\beta$-defensin 1 levels and caries experience in children. Caries Res. 2017; 51 (3): 209-215.

52. Kim J, Hu J, Lee J, Moon S, Kim Y, Jang K et al. Mutational hot spot in the DSPP gene causing dentinogenesis imperfecta type II. Human Genetics. 2005; 116 (3): 186-191.

53. Jodkowska E. Polish public caries prophylaxis programme for children and young people. Dent Med Probl. 2010; 47: 137-143.

54. Banderas-Tarabay J, Zacarías-D'Oleire I, Garduño-Estrada R, Aceves-Luna E, González-Begné M. Electrophoretic analysis of whole saliva and prevalence of dental caries. A study in Mexican Dental Students. Arch Med Res. 2002; 33 (5): 499-505.

55. Cavallari T, Salomao H, Moysés S, Moysés S, Werneck R. The impact of MUC5B gene on dental caries. Oral Dis. 2017; 24 (3): 372-376.

56. Culp DJ, Quivey RQ, Bowen WH, Fallon MA, Pearson SK, Faustoferri R. A mouse caries model and evaluation of aqp5-/knockout mice. Caries Res. 2005; 39 (6): 448-454.

57. Yu P, Bixler D, Goodman P, Azen E, Karn R. Human parotid proline-rich proteins: correlation of genetic polymorphisms to dental caries. Genet Epidemiol. 1986; 3 (3): 147-152.

58. Anderson L, Mandel I. Salivary protein polymorphisms in cariesresistant adults. J Dent Res. 1982; 61 (10): 1167-1168.

59. Anderson L, Lamberts B, Bruton W. Salivary protein polymorphisms in caries-free and caries-active adults. J Dent Res. 1982; 61 (2): 393-396.
60. Olszowski T, Adler G, Janiszewska-Olszowska J, Safranow K, Kaczmarczyk M. MBL2, MASP2, AMELX, and ENAM gene polymorphisms and dental caries in polish children. Oral Dis. 2012; 18: 389-395.

61. Li ZQ, Hu XP, Zhou JY, Xie XD, Zhang JM. Genetic polymorphisms in the carbonic anhydrase $\mathrm{VI}$ gene and dental caries susceptibility. Genet Mol Res. 2015; 14 (2): 5986-5993.

62. Hu X, Li X, Zhou J, YuM Z, Zhang J, Guo M. Analysis of the association between polymorphisms in the vitamin $\mathrm{D}$ receptor (VDR) gene and dental caries in a Chinese population. Genet Mol Res. 2015; 14 (3): 11631-11638.

63. Alyousef YM, Borgio JF, AbdulAzeez S, Al-Masoud N, Al-Ali AA, Al-Shwaimi E et al. Association of MBL2 gene polymorphism with dental caries in Saudi children. Caries Res. 2017; 51 (1): 12-16.

64. Kulkarni G, Chng T, Eny K, Nielsen D, Wessman C, El-Sohemy A. Association of GLUT2 and TAS1R2 genotypes with risk for dental caries. Caries Res. 2013; 47 (3): 219-225.

65. Izakovicova HL, Borilova Linhartova P, Lucanova S, Kastovsky J, Musilova K, Bartosova M et al. GLUT2 and TAS1R2 polymorphisms and susceptibility to dental caries. Caries Res. 2015; 49 (4): 417-424.

66. Haznedaroglu $E$, Koldemir-Gündüz $M$, Bakir-Coskun N, Bozkus $\mathrm{H}$, Cagatay P, Süsleyici-Duman B et al. Association of sweet taste receptor gene polymorphisms with dental caries experience in school children. Caries Res. 2015; 49 (3): 275-281.

67. Robino A, Bevilacqua L, Pirastu N, Situlin R, Di Lenarda R, Gasparini $P$ et al. Polymorphisms in sweet taste genes (TAS1R2 and GLUT2), sweet liking, and dental caries prevalence in an adult Italian population. Genes Nutr. 2015; 10 (5): 485.

\author{
Correspondencia: \\ Rocío Patricia Mariaud Schmidt \\ E-mail: rocio.mariaud@academicos.udg.mx
}

